\title{
Consumers Choosing Retailers On Online Market- places: How Can Retailers Differentiate Apart From The Price? - An Exploratory Investigation
}

\author{
Manuel Adler \\ manuel.adler@ymail.com \\ Szent István University - Kaposvár Campus, Kaposvár, Hungary \\ Atilla Wohllebe \\ aw@wr-publishing.org \\ WR Institute of Applied Sciences, Hamburg, Germany \\ https://doi.org/10.51137/ijarbm.2020.1.1.3
}

\begin{abstract}
Online marketplaces are becoming increasingly important for many traders. At the same time, price transparency is a challenge. To secure their profit margins and to be able to convince consumers outside of pricing, it is therefore important for retailers in online marketplaces to understand which factors besides pricing influence the purchasing decision of consumers. This paper focuses therefore on situations where the decision for a certain product is already made and where consumers are only looking for the right retailer in an online marketplace. This paper uses a binary logistic regression to investigate what consumers previous experience with retailers is and how it influences them, apart from price, delivery time, ratings and the consumer's previous experience with the retailer have. The investigation is based on 700 purchase decisions collected in a survey. The paper provides important insights into which aspects retailers should focus on in order to be able to sell successfully via marketplaces even outside of a price war. In addition, the paper suggests more in-depth research questions.
\end{abstract}

Keywords - Retailer Selection, B2C Online Marketplaces, Consumer Decision Process, Consumer Behavior, Purchase Decision

\section{Introduction}

With a turnover of around 57.8 billion euros in 2019, e-commerce now accounts for around 12 percent of German retail trade (HDE 2019, Destatis 2019). Online marketplaces such as Amazon account for a considerable proportion of this; e.g. in 2018, around 30 percent of total e-commerce sales (Amazon 2019). Respectively, online marketplaces have become an important sales channel for many traders: In a survey, around 27 percent of the retailers surveyed replied that they generate more than 50 percent of their sales via online marketplaces (ecom consulting 2019).

Marketplaces are thus an important instrument for retailers looking for or operating a distribution channel online, whereby in particular the dependence of retailers on marketplace operators is a problem in the view of many 
retailers (DHL 2018). Looking at the ten largest online shops in terms of their respective reach, taking online marketplaces into account, this suggests a clear dominance of the two online marketplaces Amazon and eBay. The market research company Nielsen (2014) puts the reach of Amazon and eBay in Germany at 41.44 and 38.38 per cent respectively, while the online shop OTTO, which is ranked third in this list, has a reach of only 8.64 per cent in Germany.

At the same time, a survey conducted by ECC Köln (2017) among some 500 consumers surveyed shows that price in particular is the central criterion when consumers choose a retailer on a marketplace, including productrelated aspects such as product description or product images.

This exploratory research is intended to investigate which factors, beyond price, are still important for consumers who select a retailer in a marketplace. To this end, potentially relevant factors will first be identified by interviews and then quantified by means of an online survey, simulating around 700 purchase decisions. The focus is exclusively on the retailer: the purchase decisions are simulated under the assumption of an already made product selection and thus exclusively with regard to retailer-related criteria.

For online retailers, a scientific view of potential ways out of the so-called price spiral is opened up: further relevant influencing factors apart from price are quantified and shown.

\section{Literature Review}

\subsection{Influencing Factors in Online Shopping and Selection of an Online Shop}

The behavior when shopping online is often described in the literature as a multi-stage purchasing process. For example, there are models with three, but also with five stages (Akbar and James 2014). Due to the symmetry of product information as a consequence of electronic markets, price can be attributed a particularly high relevance (Merz 2002). This has already been shown in numerous research studies. Both Akbar and James (2014) and Boyer and Hult (2005) show that, in addition to price as the decisive criterion for online shopping, convenience and the expected time savings play a central role. Trust in online shopping (Merz 2002), which can be increased through ratings and recommendations (Khalil 2014), is considered an important entry barrier. According to several authors there is a positive correlation between trust and sales in online trade (Mudambi and Schuff 2010, Chen, Dhanasobhon and Smith 2008).

In addition to the decision for online shopping in general, the question of how potential customers in e-commerce choose a specific online shop is also relevant. In addition to price, reputation and trust in an online shop as well as ratings and assessments play an important role. Performance in order fulfillment is also an important criterion (Chenghuan 2014). A similar correlation also applies between satisfaction or trust and long-term customer loyalty (Carlson et al. 2013), with the additional positive effect of the flow 
experience during use. Research also indicates that customer satisfaction also has a positive effect on consumers' willingness to use customer loyalty measures such as mobile apps (Wohllebe, Ross, and Podruzsik 2020).

\subsection{The Consumer Decision Process on Online Marketplaces}

When suppliers (online retailers) and consumers meet on an online platform operated by a third party (marketplace operator), this is called a marketplace (Kollmann 2000). The high level of transparency in a marketplace leads to a particular intensification of competition (Voigt, Landwehr and Zech 2003). Particularly in pricing, traders then try to compete, profit margins decrease (Akbar and James 2014, Merz 2002). This circumstance represents a challenge from the point of view of competition and antitrust law (Pressey and Ashton 2009).

From the consumer's point of view, marketplaces that transparently compare products from different suppliers in terms of price, but also e.g. retailer ratings, offer a simple purchasing process with little perceived risk and thus increase the willingness to buy (Beatty and Smith 1987, Grewal, Gotlieb, and Marmorstein 1994, Grewal, Monroe and Krishnan 1998, Teo and Yeong 2003). Especially among consumers who are less experienced in online shopping, the reputation of a retailer in a marketplace pays off positively (Yong et al. 2019). Here, in addition to information about the seller, information about the product also has a positive effect on the perceived risk (Meents and Verhagen 2018). The trustworthiness of the marketplace operator also has an indirect effect on the trustworthiness of the actual trader and thus on the consumer's decision-making process (Hong and Cho 2011). As in online shopping, order fulfillment is also an important criterion for the selection of the provider for marketplaces (Bart et al. 2005).

In the context of price or product search engines, Smith and Brynjolfsson (2001) show, that in addition to the relevance of price in general, the price of the item (rather than the total price or shipping costs) plays a particularly important role in the selection of an offer. The retailer's reputation, the delivery time and the sorting order of the offers are also highlighted as important.

\subsection{Research Gap}

After intensive literature research, all the findings on consumer behavior in marketplaces available to date relate to scenarios in which the decision for a combination of retailer and product is considered. Today, no statements have been made on how retailers should position themselves in marketplaces where the product is in the foreground and several retailers are listed among themselves as suppliers of this product.

This work is therefore particularly relevant in environments such as Amazon, probably the most important marketplace in the western world, where there is less and less presence for the individual trader: If the consumer has already decided on a product, how does he decide on a retailer? What fac- 
tors can traders use to position themselves in marketplaces where the product is clearly in the foreground?

\section{Identification of Potential Factors in the Decision- Making Process}

\subsection{Methodology}

This research will first identify potentially relevant factors influencing the decision-making process of consumers when choosing a retailer in marketplaces. For this purpose, semi-structured interviews are conducted with several consumers. The interviewed consumers are first introduced to the topic and socio-demographic data are collected.

Subsequently, the test persons are presented with a screenshot of Amazon, showing a concrete product and several retailers. The test persons are asked to explain which supplier they would choose for which reasons. The interviewer only asks questions for better understanding.

In the third step, the respondents are asked the open question as to which criteria are still relevant for them when shopping on an online marketplace in addition to those they have already mentioned.

\subsection{Results from the Interviews}

In total, interviews were conducted with twelve consumers of both sexes and various income and educational levels. The respondents cited the following criteria as relevant to them when selecting a suitable retailer: Total price, delivery costs, price composition, ratings, awareness \& experience with the retailer as well as conditions for warranty, returns and returns, the delivery origin and delivery speed.

Respondents report that they are "most interested in the price", which is "first and foremost the deciding factor". Evaluations would help to "know who I am dealing with", some are "also willing to spend more money" if the retailer is better rated. Previous experiences, on the other hand, are seen more as hygiene factors, especially if one has "had a negative experience" with a trader. In contrast, the role of delivery speed seems to be central, it is "very important", because one wants to "receive his article as quickly as possible". A higher willingness to pay for a higher delivery speed is also indicated as long as "the price is within a similar range".

Only a few details are given on the origin of the delivery and on the guarantee, return and take-back conditions. 


\section{Quantification of individual factors on the purchase decision}

\subsection{Methodology}

The potential influencing factors on retailer selection in the buying process on marketplaces, extracted from the literature and the semi-structured interviews, are summarized and transferred into a survey. In the online survey, consumers are asked to make a purchase decision for a specific trader in a fictitious scenario. The individual retailers are generated randomly on the basis of defined sets of characteristics for each variable, taking into account the potential influencing factors determined previously.

At the beginning, the respondents are asked to report their opinion of these traders in addition to a total of five, partly better known, partly less known and partly not known real traders. The respondents answer the question about their opinion of the respective trader on a likert scale. (five levels between "negative" and "positive".)

The respondent is then shown one of nine different products, each of which is one of three products from three different categories. Each respondent is presented with a total of five different offers from different retailers when they call up the page. The individual offers vary randomly, with a value from the value sets for item price and shipping costs being randomly selected for each offer on a product-specific basis. The total price is calculated from these values.

The average rating, the number of ratings and the delivery speed are also randomly generated from pre-defined quantities of values, whereby the average rating at an interval of 0.25 points allows all values between 3.5 and 5.0 and the delivery speed values "1-2 days", "3-4 days" and "5-6 days". The number of ratings is generated randomly in the interval from 50,000 to $2,500,000$.

At the end of each line, the user can choose which offer he would like to purchase and then confirm this either by clicking on "Next" or on "Again". If the user clicks on "Again", he will receive the same page with newly generated offers and can therefore make several fictitious purchase decisions.

For each respondent it is saved which offers have been displayed to him/her and which offer has been decided upon.

In addition, the respondents are asked questions about sociodemographic data.

The data from the survey is then evaluated using a binary logistic regression and the influence of the individual potential factors on the target variable (purchase or non-purchase of a product from the retailers displayed) is assessed. The individual offers of the retailers displayed together are ranked against each other and these rankings are evaluated in the further course of the survey. 


\subsection{Analysis and results}

Based on the interviews, the survey examines the influence of the following factors on the (fictitious) purchase decision: price of the product, shipping costs, number of ratings, average rating, delivery speed and opinion about the respective retailer.

A total of 697 purchase decisions are made by the respondents, with the respondents distributed roughly equally according to gender. Among the age groups, 18 to 25-year-olds account for around 70 percent and 26-35-yearolds for around 20 percent of respondents. The remainder is distributed among older respondents. About 50 percent have a high school diploma, another 30 percent a bachelor's degree. Most (around 55 percent) of the respondents come from northern Germany. With the exception of the approximately 30 percent with an income below 1,000 euros per month, the other seven income groups are represented with roughly equal frequency.

Table 1: Results of the binary logistic regression

Number of cases $\quad 3485$

\begin{tabular}{|c|c|c|c|}
\hline Goodness of fit & & & \\
\hline \multirow{2}{*}{ Likelihood Ratio-Test } & Chi²-Wert & 862 & \\
\hline & Significance & \multicolumn{2}{|c|}{$1.042 \mathrm{e}-180$} \\
\hline \multicolumn{4}{|l|}{ Fit of the model } \\
\hline McFadden-R ${ }^{2}$ & 0.254 & & \\
\hline Nagelkerke-R ${ }^{2}$ & 0.352 & & \\
\hline \multicolumn{4}{|l|}{ Coefficients } \\
\hline (Intercept) & $\begin{array}{l}B \\
4.864\end{array}$ & Significance & $\begin{array}{l}\operatorname{Exp}(B) \\
129.650\end{array}$ \\
\hline Rank total price & -0.682 & *** & 0.505 \\
\hline Rank product price & -0.225 & $* * *$ & 0.798 \\
\hline Rank delivery fee & -0.245 & $\star * \star$ & 0.782 \\
\hline Rank delivery times & -0.217 & $* * *$ & 0.805 \\
\hline Rank position & -0.079 & * & 0.924 \\
\hline Rank retailer experience & -0.271 & $\star * *$ & 0.762 \\
\hline Rank retailer rating & -0.410 & $* * *$ & 0.663 \\
\hline Rank number of ratings & -0.081 & * & 0.922 \\
\hline
\end{tabular}

Table 1 shows the result of the binary logistic regression for the available data including the quality measures for the adjustment and the overall model as well as the individual regression coefficients. A total of 3,485 purchase decisions were evaluated. 697 decisions for and 2,788 against a range of products offered by the retailers. The likelihood ratio test shows that the results are transferable to the population, the separating force of the independent variables based on McFadden- $\mathrm{R}^{2}$ and the comparison of the likelihood values taking into account the sample size based on Cox \& Snell- $R^{2}$

Consumers Choosing Retailers On Online Marketplaces: How Can Retailers Differentiate Apart From The Price? - An Exploratory Investigation 
and the proportion of the explained variance of the dependent variable by the independent variables based on Nagelkerke- $R^{2}$ are in the acceptable to good range (Backhaus et al. 2006).

The analysis measures the influence of the independent variables total price, item price, shipping flat rate, delivery time, position, respondent's opinion of the retailer, average rating in stars and the number of ratings. All independent variables are expressed as a ranking, whereby the ranking is determined by how well a quote was compared to others with whom it was displayed at the same time.

The purchase or non-purchase ( 1 or 0 ) of an offer is used as the dependent variable.

All regression coefficients have a significant influence on the purchase decision. The total price (more precisely: the ranking of an offer with regard to the total price compared to the other offers) has the greatest influence, although this contradicts the findings of Smith and Brynjolfsson (2001). The second most important factor in a user's buying decision on a marketplace is the rating of the trader on the marketplace, followed shortly afterwards by the respondent's previous opinion of the trader in question.

In contrast, the number of ratings of the trader on the marketplace and the position in the list of traders offering the product play a strongly downstream role.

\section{Conclusion}

The results of the study make it possible to extend previous scientific findings on consumer behavior when shopping online and in online marketplaces, especially with regard to the central role of price: Even if the decision for a certain product has already been made in a marketplace and now only the appropriate retailer has to be selected, the price still dominates the purchase decision, even though the prices for the same product are at least similar.

The intensified competition in online marketplaces is the central challenge that online traders have to face (Voigt, Landwehr and Zech 2003). Especially when retailers try to compete on pricing, profit margins decrease (Akbar and James 2014, Merz 2002). Although the central role of price as a factor influencing trader selection cannot be denied, the present data set does reveal two important additions: Firstly, a good average rating of the retailer on the marketplace is of central importance, and secondly, establishing a long-term customer relationship in the sense of awareness of the retailer's brand among consumers is also worthwhile: positive past experiences with a particular one have a clearly positive influence on the purchase decision.

The position of the retailer's offer in the list and the number of ratings had only a very small effect on the purchase decision: These are the factors on which marketplace traders do not have to focus first. The effect of delivery speed is surprisingly small, although this effect may be due to the way the data is collected and consumers may announce different priorities depending on the product they need. 
Here, there is an essential field for further research questions: In particular, the urgency of a need could play a central role in the weighting of delivery speed if consumers are to select a suitable retailer for a certain product in a marketplace. Furthermore, with the growing relevance of mobile apps in retail (Wohllebe, Dirrler, and Podruzsik 2020), research may be conducted depending on the device type used by the consumer. Different preferences according to income group would also be conceivable, assuming that individual price sensitivity is influenced by one's own income.

\section{References}

Akbar, S., James, P. (2014). Consumers' attitude towards online shopping: Factors influencing employees of crazy domains to shop online. Journal of Management and Marketing Research, 14(1).

Amazon (2016). Anbieter für Siemens KG39EA140 Kühl-Gefrierkombination. Online access via http://www.amazon.de/gp/offerlisting/B004R9PS7U/ref=sr_1_4_olp?ie=UTF8\&qid $=1456239878 \& s r=8$ -

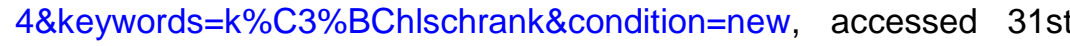
March 2016.

Amazon (2019). Annual Report / Form 10-K, p. 67. Online access via https://de.statista.com/statistik/daten/studie/374731/umfrage/nettou msatz-von-amazon-in-deutschland-und-weltweit/, accessed 20th Dec. 2019.

Backhaus, K., Erichson, B., Plinke, W., Weiber, R. (2006). Multivariate Analysemethoden - Eine anwendungsorientierte Einführung. 11. Auflage, Springer Verlag, Berlin.

Bart, Y., Shankar, V., Sultan, F., Urban, G. L. (2005). Are the Drivers and Role of Online Trust the Same for All Web Sites and Consumers? A Large Scale Exploratory Empirical Study. Journal of Marketing, 69(4). https://doi.org/10.1509/jmkg.2005.69.4.133

Beatty, S.E., Smith, S.M. (1987). External search effort: an investigation across several product categories. Journal of Consumer Research, 14(1). https://doi.org/10.1086/209095

Boyer, K. K., Hult, T. (2005) Customer Behavior in an Online Ordering Application - A Decision Scoring Model. Decision Sciences, 36(4). https://doi.org/10.1111/j.1540-5414.2005.00103.x

Carlson, J., Ahrholdt, D., Sridharan, R., Simatupang, T. (2013). New Insights Into Consumer Loyalty Of Website-Services: The Quadratic Effect Of Flow. E-Marketing in Developed and Developing Countries: Emerging Practices, Chapter 15, pp. 246-257. https://doi.org/10.4018/9781-4666-3954-6.ch015

Chen, P.-Y., Dhanasobhon, S. and Smith, M. D. (2018). All Reviews are Not Created Equal: The Disaggregate Impact of Reviews and Reviewers at Amazon.Com . Online access via http://dx.doi.org/10.2139/ssrn.918083, accessed 20th Dec. 2019. 
Chenghuan, L. (2014). Factors influencing customers' choices of online retailers. Aalto University Library. Online access via https://aaltodoc.aalto.fi/handle/123456789/12838, accessed 20th Dec. 2019.

Destatis (2019). Genesis Datenbank 45341-0001. Online access via https://de.statista.com/statistik/daten/studie/261395/umfrage/umsatz anteil-des-ecommerce-im-einzelhandel-in-deutschland/, accessed 20th Dec. 2019.

DHL (2018). Onlinehändler im Spannungsfeld von Wachstum und Marktkonzentration, p. 9. Online access via https://de.statista.com/statistik/daten/studie/937130/umfrage/gruend e-fuer-das-abhaengigkeitsgefuehl-beim-verkauf-auf-onlinemarktplaetzen-in-deutschland/, accessed 20th Dec. 2019.

ECC Köln (2017). Klick auf den ersten Blick, p. 14. Online access via https://de.statista.com/statistik/daten/studie/748037/umfrage/kriterien -fuer-die-wahl-des-marktplatzhaendlers-auf-ebay-und-amazon-indeutschland/, accessed 20th Dec. 2019.

HDE (2019). Online Monitor 2019, p. 6. Online access via https://de.statista.com/statistik/daten/studie/3979/umfrage/ecommerce-umsatz-in-deutschland-seit-1999/, accessed 20th Dec. 2019.

ecom consulting (2019). Marktplatzstudie. Online access via https://de.statista.com/statistik/daten/studie/1060181/umfrage/anteildes-gesamten-online-umsatzes-ueber-online-marktplaetze-indeutschland/, accessed 20th Dec. 2019.

Grewal, D., Gotlieb, J., Marmorstein, H. (1994). The moderating effects of message framing and source credibility on the price-perceived risk relationship. Journal of Consumer Research, 21(1).

Grewal, D., Monroe, K.B., Krishnan, R. (1998). The effects of pricecomparison advertising on buyers' perceptions of acquisition value, transaction value and behavioral intentions. Journal of Marketing, 62(2). https://doi.org/10.2307/1252160

Hong, I.B., Cho, H. (2011). The impact of consumer trust on attitudinal loyalty and purchase intentions in B2C e-marketplaces: Intermediary trust vs. seller trust. International Journal of Information Management, 31, 469-479. https://doi.org/10.1016/j.ijinfomgt.2011.02.001

Khalil, N. (2014). Factors affecting the consumer's attitudes on online shopping in Saudi Arabia. International Journal of Scientific and Research Publications,4(11).

Kollmann, T. (2000). Elektronische Marktplätze - Die Notwendigkeit eines bilateren One to One-Marketingansatzes. Published in Bliemel, F., Fassott, G., Theobald, A.: Electronic Commerce Herausforderungen - Anwendungen - Perspektiven. Gabler, Wiesbaden.

Meents, S., Verhagen, T. (2018). Reducing consumer risk in electronic marketplaces: The signaling role of product and seller information. Computers in Human Behavior ,86, 205-217. https://doi.org/10.1016/j.chb.2018.04.047

Consumers Choosing Retailers On Online Marketplaces: How Can Retailers Differentiate Apart From The Price? - An Exploratory Investigation 
Merz, M. (2002). E-Commerce und E-Business - Marktmodelle, Anwendungen und Technologien. dpunkt.verlag 2002, Heidelberg.

Moorthy, S., Ratchford, B.T., Talukdar, D. (1997). Consumer information search revisited: theory and empirical analysis. Journal of Consumer Research, 23(4). https://doi.org/10.1086/209482

Mudambi, S. M., Schuff, D. (2010). What Makes a Helpful Online Review? A Study of Customer Reviews on Amazon.com. MIS Quarterly, 34(1). https://doi.org/10.2307/20721420

Nielsen (2014). Reichweite der größten Online-Shops in Deutschland im April 2014. Online access via https://etailment.de/news/stories/Die10-groessten-Online-Shops-in-Deutschland-nach-Besucherzahlenund-Reichweite-April-2014-2571, accessed 20th Dec. 2019.

Pressey, A.D., Ashton, J.K. (2009). The antitrust implications of electronic business-to-business marketplaces. Industrial Marketing Management, Impact of Outsourcing on Business-to-Business Marketing, 38, 468-476. https://doi.org/10.1016/j.indmarman.2008.02.012

Smith, M. D., Brynjolfsson, E. (2001). Consumer Decision-Making At An Internet Shopbot. The Journal of Industrial Economics, 49(4). https://doi.org/10.1111/1467-6451.00162

Teo, T. S. H., Yeong, Y. D. (2003). Assessing the consumer decision process in the digital marketplace. Omega, 31(5). http://doi.org/10.1016/S0305-0483(03)00055-0

Voigt, K.-I., Landwehr, S., Zech, A. (2003). Elektronische Marktplätze - EBusiness im B2B-Bereich. Physica-Verlag, Heidelberg.

Wohllebe, A., Dirrler, P., Podruzsik, S. (2020). Mobile Apps in Retail: Determinants of Consumer Acceptance - a Systematic Review. International Journal of Interactive Mobile Technologies (iJIM),14(20). https://doi.org/10.3991/ijim.v14i20.18273

Wohllebe, A., Ross, F., Podruzsik, S. (2020). Influence of the Net Promoter Score of Retailers on the Willingness of Consumers to Install Their Mobile App. International Journal of Interactive Mobile Technologies (iJIM),14(19). https://doi.org/10.3991/ijim.v14i19.17027

Yang, Y., Sun, X., Wang, J. (2019). The value of reputation in electronic marketplaces: A moderating role of customer experience. Journal of Research in Interactive Marketing,13(4), 578-601. https://doi.org/10.1108/JRIM-11-2018-0151

Zhu, Y., Li, Y., Leboulanger, M. (2009). National and Cultural Differences in the C2C Electronic Marketplace: An Investigation into Transactional Behaviors of Chinese, American, and French Consumers on eBay. Tsinghua Science \& Technology, 14, 383-389. https://doi.org/10.1016/S1007-0214(09)70055-0 